\title{
Carnets
}

Revue électronique d'études françaises de l'APEF

Première Série - 4 Numéro Spécial | 2012

Invasions \& Évasions

\section{Franceses, mulheres e outros estrangeiros : de um sermão de 1811 à poesia panfletária de Catarina de Lencastre}

Maria Luísa Malato Borralho

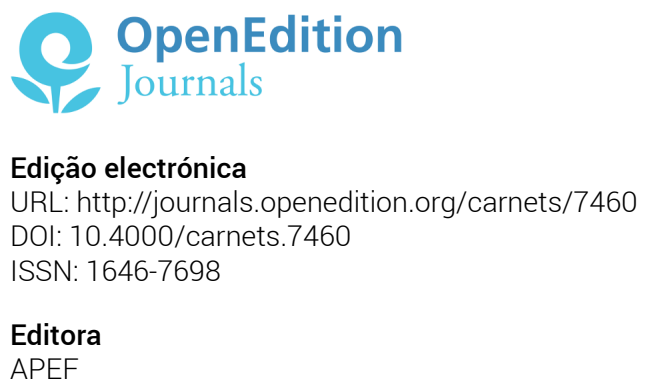

Edição impressa

Data de publição: 1 Junho 2012

Paginação: 99- 119

Refêrencia eletrónica

Maria Luísa Malato Borralho, « Franceses, mulheres e outros estrangeiros : de um sermão de 1811 à poesia panfletária de Catarina de Lencastre », Carnets [Online], Première Série - 4 Numéro Spécial | 2012, posto online no dia 23 junho 2018, consultado o 20 abril 2019. URL : http:// journals.openedition.org/carnets/7460 ; DOI : 10.4000/carnets.7460

\section{(a) $(1) \Theta$}

Carnets est mis à disposition selon les termes de la licence Creative Commons - Atribution - Pas d'utilisation commerciale 4.0 International. 


\title{
FRANCESES, MULHERES E OUTROS ESTRANGEIROS \\ De um sermão de 1811 à poesia panfletária de Catarina de Lencastre
}

\author{
MARIA LUÍSA MALATO BORRALHO \\ Universidade do Porto \\ Instituto de Literatura Comparada M. Losa1 \\ mlmalato@gmail.com
}

\section{Resumo}

Os estudos literários têm desvalorizado a poesia panfletária dos séculos XVIII e XIX. Ela é o exemplo de uma literatura circunstancial e menor, ou a permanência de uma moral ao serviço de uma ideologia. Em qualquer dos casos, um corpo estranho na História Literária que ficciona o nascimento espontâneo do « indivíduo romântico », da "sentimentalidade feminina", e até de uma "arte pela arte", amoral e apolítica. E, no entanto, a poesia panfletária que nasce das invasões francesas é a melhor prova dessa mesma historiografia: evidencia o caráter mediático da Literatura, o hibridismo da poesia épica e lírica, mas também a ambiguidade retórica de uma « literatura» que pode ser afinal uma arma do género, evadindo as mulheres do espaço doméstico. Estes aspetos se exemplificarão com a obra de uma poetisa esquecida: Catarina de Lencastre, pretexto adicional para rever os cânones da nossa História Literária.

\begin{abstract}
Studies about Romanticism have often neglected pamphletary literature, seen as "too circumstantial » or « too engaged » to fit the concept of such a sentimental period. On the other hand, Feminine Studies are all about the demands of the sentimental gender. But perhaps we could find on pamphleteers the best example of the complexity of Romanticism and Feminine Literature: new publics' vitality, lyrical and epic poetry's hybridism, and also new rhetorical strategies of women's literature. This thesis can be best viewed through the example of Catarina de Lencastre's poetry, during the War of the Oranges and the French Invasions. Forgotten by Literary History, Catarina de Lencastre is, after all, another good pretext to review the Literary History's canon.
\end{abstract}

Palavras-chave: Invasões, Mulher, Poesia panfletária, Catarina de Lencastre, Balsemão.

Keywords: Invasions, Women, Pamphletary Literature, Catarina de Lencastre, Balsemão.

\footnotetext{
1 Este estudo/ artigo/ ensaio foi elaborado no âmbito do Projecto "Interidentidades" do Instituto de Literatura Comparada Margarida Losa da Faculdade de Letras da Universidade do Porto, Unidade I\&D financiada pela Fundação para a Ciência e Tecnologia, integrada no Programa Operacional Ciência e Inovação 2010 (POCI 2010), do Quadro Comunitário de Apoio III (POCI 2010-SFA-18-500).
} 
A 1 de Janeiro de 1811, na Igreja de S. Paulo, em Lisboa, um honesto cristão ouviu coisas espantosas da boca do pregador. Que não se deviam odiar os invasores franceses, isto apesar de, nos últimos anos, terem passado as nossas fronteiras e destruído os nossos bens. Que era próprio de um seguidor de Cristo não odiar, ainda os piores inimigos. Que não se deviam pronunciar pragas contra esses demónios e desejar a sua morte: a própria incitação era excessiva, pois a salvação da propriedade não era razão suficiente para o assassínio... Os que, até àquele momento, tinham tido o padre por bom pregador saíram da igreja duvidando dos seus conhecimentos teológicos, pois assim viam transformar o amor "ao próximo" numa insana "recomendação geral" (Carneiro, 1811: 11). Perplexidade grande era a de todos, até porque se recordavam de lhe ter ouvido outras coisas muito sensatas, como a necessidade de as mulheres serem recatadas, a conveniência de saírem toucadas para a rua; a maior circunspeção que deviam mostrar na igreja... Pedia por isso ele, alma sem dúvida conscienciosa, um fundado parecer a Frei José de S. Cyrillo Carneiro, pessoa abalizadíssima a dá-lo, a crer nos títulos com que se assinava, já que Frei José era, não só Religioso da Ordem da Senhora do Carmo, como Doutor pela Universidade de Coimbra, Censor Régio do Santo Ofício e ainda Examinador das três Ordens Militares.

Invasões de Estrangeiros e Evasões Femininas

Deixemos por ora a questão de saber se a resposta dada por Frei José de S. Cyrillo Carneiro veio a dar razão ao pregador da Igreja de S. Paulo.

O que há de mais curioso neste texto de 1811 são as explícitas referências a dois "lugarescomuns", isto é, retoricamente, a "lugares"/ argumentos que se partilham sem discussão de especialidade. O mais interessante parece ser a estreita ligação dos dois lugares-comuns evocados: o natural lugar dos estrangeiros (fora das fronteiras nacionais), e o natural lugar das mulheres (no recato da casa). Cada um no seu sítio. Os naturais e expectáveis lugares das mulheres, bem como os naturais e expectáveis lugares dos estrangeiros, revelavam afinal semelhantes ou próximos "lugares" retóricos/ caixas da memória de onde nos vêm (para a Inventio/ Invenção) argumentos semelhantes ou próximos. Saber que o lugar dos estrangeiros estava fora das nossas fronteiras era tão sensato quanto saber que o lugar das mulheres estava dentro de casa. Se uns e outros se aventuravam fora dos seus territórios deviam sempre fazê-lo com circunspeção, ficando naturalmente sujeitos a julgamentos sumários (éticos, morais, teológicos). É próprio dos "lugares-comuns" não exigirem conhecimentos próprios", ou seja, derivados de competências especiais ou de formações especializadas. Delimitado pela "vox populi"-"vox Dei", quer o espaço dos estrangeiros quer o espaço das mulheres implicava sempre o respeito pelas fronteiras, fosse ela uma linha no 
mapa ou a soleira da porta. E em ambos os casos a passagem provocante dessa fronteira era motivo para o castigo, ainda que em graus diferentes, e por culpas diferentes.

Se a noção de "estrangeiro" é frequentemente compreendida através da propriedade de um "espaço" (próprio e impróprio"), já muito mais raramente encontramos nos "lugarescomuns" sobre a mulher uma reflexão alargada sobre o espaço que lhe é próprio ou o espaço em que ela é tratada como "invasora" ou "estrangeira". A questão é desde logo paradoxal quando se considera que a virtude feminina é a da sua invisibilidade no "espaço" público, supostamente um "lugar-comum", onde, afinal, ela não tem lugar. Há na "virtude" um facto singular, patente desde logo na etimologia do substantivo. A "virtude" é o que é próprio do "homem" (em latim "vir"). E, assim, as reflexões abstratas sobre a virtude implicam, invariavelmente, uma demonstração de força (força física, desde logo, depois moral). Não uma força restrita ao corpo do próprio, musculado, mas uma força pública, que inscreva as qualidades do indivíduo num espaço exterior. É próprio da virtude nacional, do patriotismo, não só a força como a exibição da força. É próprio da virtude masculina a possibilidade de demonstrar, no espaço da sua comunidade, a sua potência física e a sua potência moral, ainda que sob formas limitadas e disciplinadas. Para Aristóteles, a "arété" é um ponto de equilíbrio ("meson") entre as emoções e as ações públicas, morais ou intelectuais, sendo então o principal intuito do Legislador a conformação do cidadão a um hábito social, a uma prática, que esteja de acordo com a sua natureza social. Em todo o caso, a virtude tem de ser um hábito em contexto (num tempo e num espaço) e nunca uma atitude pontual. Necessita por isso de um comportamento repetido, coerente e reconhecido, pois só praticando determinados atos na presença do perigo, e estando familiarizados com o medo e a confiança, nos tornamos perante os outros corajosos ou cobardes (Aristotle, Ethica, II: 1103b).

Ora é muito interessante que, vista sob este aspeto espacial, a virtude feminina tenha de ser muito diferente da masculina, limitada que ela está por uma diferente maneira de ocupar espaços (os seus espaços e os alheios). Aristóteles parece ter sido dos primeiros filósofos a considerar as dificuldades inerentes à noção de "espaço", partindo ele do princípio de que o "espaço" se define, não tanto pela fronteira geométrica, mas pelos elementos que ocupam o espaço. É a mudança dos corpos que ocupam o espaço que nos torna conscientes de que o espaço muda (Aristotle, Physicae, IV: 208b). É comum afirmarse que foi um outro livro de Aristóteles, sobre a geração animal, que influenciou grande parte das considerações teológicas e fisiológicas sobre a natural inferioridade da mulher (Darmon, 1983: 19-32). Uma conceção biológica da perfeição hermafrodita, de que o homem estaria mais próximo, parece-nos todavia menos importante do que a que a conceção biológica que remete a mulher para uma especialização funcional ligada à maternidade. Sendo a mulher o único ser que pode fazer a gestação e aleitamento dos filhos, restringe-se a sua 
funcionalidade ao espaço da casa, enquanto for este o espaço de gestação e crescimento dos filhos. Sendo o homem o único ser que, sem dano sobre a continuidade da espécie, está livre para o conflito territorial, dentro e fora de casa, mais facilmente se the atribui o espaço público. Com efeito, a distinção sexual entre machos e fêmeas é a característica que a teoria aristotélica mais pertinentemente opõe na natureza dos animais de sangue quente. Base primeira das distinções funcionais, à fêmea está sobretudo associada a manutenção da espécie e ao macho a manutenção dos indivíduos (alimentação, território). Aristóteles cita e utiliza em diferentes momentos uma persistente escala pitagórica que associa o macho à unidade, à clareza e ao limite; e a fêmea à pluralidade, à sombra e à imprecisão do mesmo espaço (Aristotle, Metaphysicae, I: 986ํㅜ). É essa tábua de correspondências que ainda hoje explica sem dúvida as pertinências semânticas do género, em palavras como "ovo"/ "ovas", "poço"/ "poça", "lago"/ "lagoa", "modo"/ "moda"...

As correspondências conotativas entranham-se, sem que se estranhem. Em 1650, Francisco Manuel de Melo dá a submissão da mulher como ordem cósmica: o homem é Sol, astro público; a mulher Lua, porque, sem luz própria, reflete ainda assim a pública que pertence a seu marido (Melo, 2003: IV). É certo que Francisco Manuel de Melo não pode ser só visto como um moralizador que se insurge "contra a liberdade das mulheres" (apesar de ser significativo que o próprio autor, na apresentação "Aos Leitores", já se tente defender dessa acusação). Francisco Manuel de Melo critica o marido que se perde em caçadas, folguedos, banquetes, jornadas ou viagens, ou nem sequer tem hora para regressar a casa (Idem XL, XLIX, XLI). Recomenda-lhe que não isole do mundo a mulher, mandando fazer em sua casa duas e três comédias cada ano e a continue a galantear e admirar (Idem: XLVII, XXXI-II, XLII). Mas mais uma vez se pressupõem espaços próprios. Um astro como o Sol reina de dia e no espaço político. A Lua veladamente e no espaço íntimo. Consequentemente, não gaba as mulheres que querem ler comédias e sabem romances de cor (Idem: XXVI). E ainda que ele afiance não querer senão que se goste do que é justo que tenha gosto, acaba por deitar as culpas, não às novelas, mas às mulheres. Estas, por lerem as novelas, acabam fugindo com mancebos do lugar, não cuidando Francisco Manuel de Melo das culpas e das leituras dos mancebos do lugar que com elas fogem (Ibidem). A "ocupação" da mulher e a mulher "ocupada" são os sinais desse espaço fronteiriço da mulher, visto claramente como espaço não só "recatado", mas também como espaço "menor" e controlado (afinal de contas, "ocupado", invadido).

Disse que seria bom ocupar a mulher no governo doméstico; e é bom, e é necessário, não só para que ela viva ocupada, senão para que o marido tenha menos esse trabalho. Coisas tão miúdas não é bem que pejem o pensamento de um, homem; e para os da mulher são mais convenientes (Idem: XIII, itálico nosso). 
Também Rousseau, autor do revolucionário Discours sur l'origine et les fondements de l'inégalité parmi les hommes (mesmo se evocando, ao contrário de Francisco Manuel de Melo, as desvantagens da vida de Corte) vem afinal a reproduzir em Émile, muito velhos argumentos sobre os tácitos contratos funcionais e espaciais entre homens e mulheres:

Dans l'union des sexes chacun concourt également à l'objet commun, mais non de la même manière. [...] L'un doit être actif et fort, l'autre passif et faible: il faut nécessairement que l'un veuille et puisse, il suffit que l'autre résiste un peu. $\mathrm{Ce}$ principe établi, il s'ensuit que la femme est faite spécialement pour plaire à l'homme. Si l'homme doit lui plaire à son tour, c'est d'une nécessité moins directe: son mérite est dans sa puissance; il plaît par cela seul qu'il est fort. Ce n'est pas ici la loi de l'amour, j'en conviens; mais c'est celle de la nature, antérieure à l'amour même. Si la femme est faite pour plaire et pour être subjuguée, elle doit se rendre agréable à I'homme au lieu de la provoquer. (Rousseau, 1971 : III, 243)

Criticando uma sua admiradora que Ihe pergunta que livros ler, pensando com eles formar o seu discurso público, Rousseau teme que ela se transforme numa mulher de corte. Responde invariavelmente que a mulher não deve desejar ser e fazer como o homem, ser urbano e cioso do seu território. Pois "[...] faite pour obéir à un être aussi imparfait que l'homme, souvent si plein de vices, et toujours si plein de défauts, elle doit apprendre de bonne heure à souffrir, même l'injustice et à supporter les torts d'un mari sans se plaindre." (Rousseau, 1971 : III, 253)

Sendo viciosa ou sã a vida pública, deve a mulher ser dela excluída, por não ser esse o seu espaço natural (o que lhe é dado pela natureza). Afinal, em alternativa a Rousseau, aquela leitora-filósofa francesa bem podia ler o pequeno opúsculo que saiu em Portugal, no ano de 1782, com as Instruções ás Senhoras Cazadas para viverem em paz, e quietação com seus Maridos:

Se não achar em seu Marido as boas condições, talento, e conveniencias temporaes que dezejou e lhe prepuzerão, não se queixe de quem a aconselhou a tal casamento. Considere que, quando assim o dispoz ou o permittio Deus Nosso Senhor, devia convir-Ihe para salvação de sua alma, se levar seus trabalhos e cruz com muita paciência. (S.A., 1782: 4)

Eram estas opiniões comuns, sê-lo-iam muito depois, ainda. Espacialmente falando, ao homem cabe conquistar/ ocupar, à mulher ser conquistada/ ocupada. Ao homem sair, à mulher esperar o seu regresso. Ao homem desejar, à mulher ser desejada. 
Linguisticamente, ao homem cabe a palavra pública, à mulher o silêncio público. Não admira por isso que o discurso feminino se transcreva à oralidade doméstica, raramente chegando ao manuscrito, sendo intransmissível pela cultura impressa, desaparecendo frequentemente sob um "discurso mudo" (Fentress/ Wickam, 1992: 172). A virtude feminina consiste sobretudo num silêncio público, em "não ser falada", em "não andar nas bocas do mundo": “Il n'importe pas seulement que la femme soit fidèle, mais qu'elle soit jugée telle par son mari, par ses proches, par tout le monde" (Rousseau, 1971: III, 245). E se antes a razão natural era divina, nos séculos XVIII e XIX, sob uma ideologia laica, a razão tornou-se claramente científica. Não é agora credivelmente evocada a costela de Adão de que seria extraída a mulher. Agora se considera tudo o que, do ponto de vista anatómico, empurra o homem para a vida pública, para o exterior (os músculos salientes, a exibição do pénis, a ejaculação do esperma), e paralelamente tudo o que empareda a mulher no recato doméstico (a ausência de músculos, a interioridade da vagina, a perda de sangue do útero, a utilidade dos seios).

Julien Joseph Virey, em 1810, considera a sua atividade de naturalista suficiente para dissertar objetivamente De l'influence des femmes sur le goût dans la littérature et les beauX-arts pendant le XVIle et XVIIle siècle: pois, tendo pesado e medido inúmeros crânios, pode afiançar que os masculinos contêm pelo menos mais três ou quatro onças de massa cinzenta, o que demonstraria, uma vez mais, a sabedoria infinita da Natureza, que dotara o homem de uma igual habilidade para as artes militares e para as lutas do espírito (apud Darmon, 1983 : 184). Também no exaustivo Système physique et moral de la femme ou Tableau philosophique de la constitution de l'état organique, du tempérament, des mœurs et des fonctions propres au sexe, da autoria do Dr. Pierre Roussel (publicado em 1775, mas reeditado sucessivamente ao longo do século XIX, indo já na sexta edição em 1813), se pode ler que as fibras do corpo feminino, sendo mais frágeis e formando um tecido mais mole, estão na origem da vivacidade e superficialidade femininas, concedendo à mulher quer a graça da imaginação, quer uma diminuída capacidade de raciocínio. A própria passagem da puberdade para a idade adulta (que no caso do homem o faria dar um salto qualitativo e o afastaria das feições infantis) provaria essa eterna infantilidade feminina: voz aguda, pele fina, moleza dos músculos, e também "quelque chose du temperament propre aux enfants" (Roussel, 1845: 24).

"Ce ne sont pas nos institutions, c'est la Nature qui parle", assegura Virey (apud Darmon, 1983 : 184). Tal preterição servirá certamente para ilibar da responsabilidade as instituições políticas e, indiretamente, os homens que as dominam. Muito próximos destes andarão os argumentos que (até meados do século XX) impedirão as mulheres de participar mais ativamente na vida pública. A começar pelos que são apresentados na Dedução Philosophica da Desigualdade dos Sexos e de seus Direitos Politicos por Natureza, obra, de 
um anónimo R. F. C., que sai oportunamente em 1822, no contexto da discussão da Constituinte, onde se prova a natural volubilidade feminina e a sua incompatibilidade com o voto.

Todavia, se tais textos avançavam com tais preterições, era porque antecipavam argumentos contrários. Significativa, pois, nos parece ser a crescente tensão entre os que sublinhavam as fronteiras femininas e os que as contestavam. A mesma tensão que motiva a perplexidade do cristão que interpela Frei José de S. Cyrillo Carneiro, no início do ano de 1811, que vê com igual escândalo impunes as mulheres que saem à rua sem recato e a aceitação dos estrangeiros pelo pregador. Como aceitar aquelas fora de casa e os estrangeiros dentro das nossas casas?

A questão implícita na perplexidade deriva já das oposições entre o poder da Natureza e o poder da Cultura. A Cultura, não somente como a verbalização de um hábito/ ritual sancionado pela Natureza dos sexos, mas como a verbalização de um estado imaginado, que pressupõe a correção da nossa bestialidade natural.

Refletindo essa tensão, o artigo da Encyclopédie, no verbete "Femme", tem duas entradas: a anatómica e a jurídica. Se, do ponto de vista anatómico, os argumentos do artigo parecem continuar a velha ideia aristotélica de que a mulher é um homem imperfeito, do ponto de vista jurídico, os argumentos evocados põem em causa os que se baseiam na natureza para justificar a autoridade masculina:

Cependant les raisons qu'on vient d'alléguer pour le pouvoir marital, ne sont pas sans réplique, humainement parlant ; et le caractère de cet ouvrage nous permet de le dire hardiment. II paraît d'abord $1^{\circ}$. qu'il serait difficile de démontrer que l'autorité du mari vienne de la nature; parce que ce principe est contraire à l'égalité naturelle des hommes ; et de cela seul que l'on est propre à commander, il ne s'ensuit pas qu'on en ait actuellement le droit : $2^{\circ}$. l'homme n'a pas toujours plus de force de corps, de sagesse, d'esprit, et de conduite, que la femme: $3^{\circ}$. le précepte de l'Ecriture étant établi en forme de peine, indique assez qu'il n'est que de droit positif. (AA. VV., s.d., online: $\mathrm{VI}, 471)$

Não estando a autoridade na natureza dos sujeitos, sendo a força do espírito pelo menos tão importante quanto a força do corpo, e ficando demonstrada a convencionalidade do castigo, não seria pois de concluir que a autoridade masculina radicava nas instituições? Que eram elas que tacitamente impunham um espaço? Sem dúvida que historicamente se foram introduzindo no espaço diferentes elementos que levam a tal perceção. Seja ele o espaço do corpo, o espaço da casa ou o espaço da paisagem (como sublinharia Aristóteles, o espaço não é tanto uma questão de limite geométrico, mas sobretudo a perceção do que metemos no espaço). Mas não poderia conceber-se uma inversão do processo constitutivo 
do espaço feminino e/ou masculino, imaginando-se um espaço primitivo, sem convencionalidade (a mulher "ingénua e pura") ou projetando um espaço futuro, composto por novos elementos e por novas convenções?

Seria preciso talvez falar primeiro do espaço do corpo, o espaço mais íntimo, ainda que frequentemente marcado pela futilidade do adorno ou invisibilidade da virtude. Não será por acaso que, antes de ocupar o lugar dos homens, a mulher se mascara de homem, lhe veste a pele, ensaiando os novos papéis.

E depois passarmos para o lugar da casa, o lugar da "dona de casa", que vai mudando nas divisões e nos móveis. Nos finais do século XVIII e princípios do século XIX, a casa distinta de cada aristocrata ou novo rico torna-se, não maior, mas mais complexa, rasgando-se as janelas, fazendo-se nela construir um pequeno salão de baile, ou até um teatro privado, criando-se novos espaços íntimos, como o "boudoir", que compensam a maior agitação do espaço público, do "salon"...

Para só depois considerar o lugar exterior, a rua, a igreja, a praça, a cidade. Os lugares públicos, onde o homem se bate e se exibe, onde o homem fala, escreve e publica o que escreve.

\section{A Poesia Panfletária de Catarina de Lencastre}

Recordamos a fama de sécia que tinha D. Catarina de Lencastre, primeira Viscondessa de Balsemão, esposa do embaixador português em Londres, depois Ministro do Reino, em Lisboa. Talvez roçasse a extravagância. Um jovem peralvilho comenta em voz alta o verde-alface do vestido da Viscondessa, desdenhando o conteúdo, já um tanto magro e seco: "- Tanta salada para tão pouco peixe..." (Borralho, 2008: 109-110).

Manuel de Figueiredo, na peça Os pais de Família (de 1773, mas publicada em 1804) exemplifica pormenorizadamente algumas extravagâncias do vestuário, por vezes a masculinização da mulher e a correlativa efeminização do homem:

Ellas querem ser homens./[...] Elles pelo contrario [...]./ Vemo-las de casaca, de rabicho,/ Faca de mato, botas, de chapéu,/ Sem brincos nem garganta; e algum tempo/ 'Té fazião a barba, até trazião/ Cabelleira de bandas. Inda as vi/ De cabello cortado sobre a testa/ $O$ corpo à mangalaça, sem feitio./ Nós então he que andamos de espartilho:/ he que púnhamos cor, branco, e sinaes,/ A cara polvilhada... Isso era de hontem./ E hoje, se repara, com mil tranças/ Ornamos as cabeças; gris, popas;/ Furamos as orelhas: empregamos já fitas cor de rosa nas castanhas: / Por formas de çapatos de mulher/ Se fazem já os nossos sem talões. (Figueiredo, 1804: I, 7) 
A moda talvez tivesse sido, na verdade, a primeira manifestação cultural de uma provocação funcional e espacial, ainda que possa ser vista como estratégia "inocente". Ou talvez porque pode ser vista enquanto tal. Em Catarina de Lencastre ou em muitas outras "mulheres da moda".

Na Disputa devertida das Grandes Bulhas que teve hum Homem com sua Mulher, por Ihe não querer deitar huns fundilhos n'huns calçoens velhos, os calções velhos já não merecem a atenção da mulher, ocupada que ela anda agora a cuidar dos seus vestidos, da limpeza da casa, da higiene do cão: " - Se não tratar de ser melhor Mulher/ Olhe que eu heide uzar do meu poder!". E a tudo responde a mulher, com argumentos "de Mulher da Moda": “- Eu sou sua Mulher, não sua preta. [...] Tome para servir-se huma criada,/ Já que a mulher não presta para nada". A peça acaba com o Homem a bater na Mulher, e com ela a jurar que aprendeu com a "massada" (Anón., 1789: 8 e 13). Mas é significativo que a Retórica masculina vença assim com tão fracos argumentos retóricos, aqui reduzidos aos da força física. Sinais certos de fraqueza na disputa verbal.

Invariavelmente, a culpa é dos invasores (dos franceses e das mulheres), e isto ainda antes da Guerra das Laranjas e das Invasões Francesas. A mulher que se aperalta, cedendo a modas estrangeiras, é por isso culpada já de dois crimes: o de sair de casa para mostrar-se e o de se deixar tão facilmente invadir. Crimes que podem ser lidos ao mesmo nível da provocação política, já que inconcebíveis ambos no Século de Oiro das Descobertas, em que os portugueses ditavam as leis do mundo e não eram por os outros manobrados, e as mulheres e os homens se diferenciavam bem nas preocupações e adornos:

No século dourado/ Quando as gentes de luxo não sabião,/ Sim, da honra e valor com que vivião,/ Cobrião a cabeça os Portuguezes/ Com férreo capacete;/ ServiaIhes o arnez de sobretudo,/ De curta niza o chapeado escudo./ Huma buida cortadora espada/ De horroso pezo;/ E segundo das forças que prezumo,/ Davão pancadas que botavão fumo. [...] Eu desejava que estes bons Peraltas/ De çapatinhos leves/ Com fivelas de prata, Amaltezados,/ Jogassem nesse tempo as caneladas./ Temposditosos! Tempos desejados!/ Agora he que eles lembrão;/ Porém não somos nada neste Mundo/ e de todo Lisboa vai ao fundo./ Hoje não há senão uns bonecrinhos/ De Francezes costumes,/ Imensa fidalguia imaginada,/ Basófia tudo, e fundamento nada. (Costa, 1788: 8 e 10)

Para além desta mudança do espaço do corpo, deveríamos talvez reconsiderar o significado do espaço da casa, das divisões da casa. A invenção do salão e do "boudoir", onde a mulher institucionalmente amua. Ou a novidade dos "psychés", onde a mulher agora legitimamente "pensa", ou une o corpo à alma. 
Catarina de Lencastre, como outras mulheres do seu estatuto social, "promove" salões, protege poetas. Promove, promovendo-se. Não será por modéstia que passa um ano, entre 1774 e 1775, a preparar a sua aparição nos salões de Londres. É sabido que, durante esse período, Catarina de Lencastre aprende línguas estrangeiras, lê poetas estrangeiros (Borralho, 2008: 60). Só depois, os seus salões acolherão escritores, diplomatas, políticos. Protegê-los-á com a ideia de, sob o prestígio masculino, ser agora parte de um processo de aculturação. Ainda que somente no espaço social da aristocracia e alta ou média burguesia, a mulher já não deseja somente inspirar poetas: faz poemas, lê, influencia, escreve. Por vezes, mas ainda raramente, publica.

Catarina de Lencastre ganha fama de influenciar politicamente o marido, Luís Pinto de Sousa. Bocage, Tolentino, a Marquesa de Alorna escrevem a Catarina de Lencastre e dedicam-Ihe poemas, esperando uma ou outra benesse do Ministro. O Duque de Lafões, irmão do rei, comentará ao receber uma carta anónima que the recordava a utilidade de regressar a Lisboa: "Acabo de receber pelo correio uma carta bem curiosa, e é decerto do Catrinão para me assustar!" (Carvalho: 1982: 24)...

Da sociabilidade do "boudoir" (sala privada onde a mulher pode amuar) à sociabilidade do "salon" (sala privada onde a mulher pode receber políticos e poetas), a mulher torna-se progressivamente ativa (cf. Anastácio, 2005ª). Excluída (ou marginalizada) a mulher da academia, o seu boudoir e o seu salão eram assim uma espantosa invenção de compromisso: um espaço privado que a "dona de casa" tornava público (Malato, 2009: 47$50,111-115$ ). E há uma notável contradição (ou ironia) naquele folheto de 1823 , em que Zacarias Alves Faca coloca instrutivamente várias mulheres numa Academia a "discorrer academicamente sobre as suas fraquezas" (Faca, 1823)! Estranha academia de mulheres que demonstra a impossibilidade de academias femininas! Talvez seja esta uma prova de que, pelo menos no mundo virtual da Literatura, as Academias femininas, espaço público (e não somente os salões, ainda espaço privado) podiam perfeitamente existir.

Em Portugal, a chegada ao trono de uma mulher, D. Maria I, talvez seja um fator político relevante, causa remota de alguns textos de defesa e exaltação da mulher. Desde logo, a reedição, em 1785, do já esquecido livro de Rui Gonçalves Dos Privilegios e Prerrogativas que o género feminino tem por direito comum e ordenações do Reino..., de 1557). Mas também a argumentação usada no Discurso que fizerão duas Senhoras portuguezas depois de lerem o papel dos Conselhos que deo hum Brasileiro (folheto de cordel de 1789), em que parecem demonstrar mais conhecimentos de Filosofia e Lógica que o seu delator:

Tu bem vês que ele juntou/ Mil cousas sem digistão:/ Máos nomes, indignas frases,/ Tudo alheio da razão,/ A dança, o café, o chá,/ O passeio divertido,/ O saber jogar as 
armas,/ Isto tudo he permitido:/ Só entre as gentes incultas/ Se pode isto criticar/ Mas não entre a Sociedade/ que se sabe regular. [...] Animaes irracionaes/ nos chama: não leva a palma,/ Pois aquelles animaes/ Não têm três potencias n'alma. (Anón, 1789: 8 e 12)

É nestes vários contextos espaciais (do corpo e da casa) que se inscreve a mudança de um espaço público exterior. Em tempo de paz, a reformulação do corpo e da casa são transgressões dissimuladas e permitidas. Avatares de Penélopes, as mulheres parecem tecer, quando na verdade esperam ainda e tramam já. Quase sem deixar sinais. Muitas vezes ainda em "discurso mudo", evitando o texto impresso e até mesmo o manuscrito.

Catarina de Lencastre raramente escreve. A poesia sai-Ihe de um jorro, enquanto as mãos estão ocupadas na costura ou nos afazeres da casa permitidos à esposa de um ministro do reino. É talvez significativo o facto de, por vezes, as suas poesias se encontrem nas costas de uma carta que acompanhara quatro caixas de morcelas de Arouca, uns figos ou uns morangos (Borralho, 2008: pp. 158-9). Escreve muito sobre coisas banais, saudades, aniversários, burricadas, ou presentear alguém com uma garrafa de vinho do Porto. Poucos manuscritos autógrafos chegaram até nós. Se chegaram alguns poemas, tal se deve aos que the foram registando os poemas ditos, ou organizando os papéis soltos em coleções guardadas quase sempre na livraria da família (Borralho, 2008: 14-17).

Mas é num contexto de mudança, entre uma literatura oral e uma literatura escrita, que devemos ler a poesia panfletária de Catarina de Lencastre, escrita em tempo de guerra, a partir de 1801. Sobretudo aqueles poemas que surgem em contexto "revolucionário", durante a Guerra das Laranjas e a Guerra Peninsular, episódios sucessivos das Invasões francesas. Com efeito, a poesia militante de Catarina de Lencastre aparece sobretudo neste contexto histórico das invasões, e o tema marca as cinco coleções datadas entre 1801 e 1813 (distinguindo-se claramente do primeiro conjunto de cinco coleções, compiladas entre 1788 e 1793, e parcialmente do terceiro conjunto, o que antecede a guerra civil, e é composto pelas coleções de 1820 e ainda aquela em que a autora estaria ainda a trabalhar quando faleceu, em 1824). A esta poesia não basta o salão: ela pede o teatro e a rua. Das primeiras composições de Catarina de Lencastre a ser impressas, as que maior divulgação parecem ter são as políticas: Aos Amigos da Pátria [s.l., s.d. 1808?], O Reconhecimento dos nossos fiéis alliados [s.l., s.d.], que circula normalmente anexado ao anterior...

Entre as odes contra os invasores e os sonetos sobre a liberdade, entre as elegias aos soldados portugueses e as epístolas a parentes e amigos, se vai percebendo um jogo de espelhos em que as Invasões Francesas parecem proporcionar as evasões de algumas mulheres-escritoras. 
É indispensável reconstruir o contexto histórico, para compreender a ousadia de uma mulher que, sendo de origem nobre, declama poesia, nos teatros de S. João do Porto, e de S. Carlos em Lisboa. Pode Catarina de Lencastre fazê-lo porque é nobre, ou apesar de o ser? Como medir os graus da ousadia? Parece estranho imaginar Catarina de Lencastre cantando a guerra, exortando os soldados que partem para a batalha a lutar contra os invasores franceses, celebrando-Ihes as vitórias.

A Cultura das Luzes tem alvores lentos. Ao longo do século XVIII, quer os textos mais provocantes quer os mais sub-reptícios acabam por se digladiar com o espetro da censura ou da indiferença (v.g., Araújo, 2004: 199 ss.). Mas é inegável que, ao longo da segunda metade do século XVIII (primeiro quase só através dos livros e, a partir especificamente de 1789, através da discussão da Revolução Francesa), se vão reformulando os conceitos políticos, religiosos, económicos e estéticos (Araújo, 2003: 68 et passim).

De uma forma quase impercetível se vai impondo, na escrita e nos palcos, esta poesia panfletária de Catarina de Lencastre, ainda nas mais antigas composições das primeiras coleções, dos anos 80. Cedo incluíra na sua poesia, as imagens herdadas de Sá de Miranda. É certo que, já na primeira coleção, de 1788, se referem algumas situações de corte. Irrompem, aqui e ali, as "Machiavelicas finezas" do sagaz Ministro, os atrevimentos do cortesão que com finezas persegue os favores do Rei. O desterro do Marquês de Pombal, e depois a sua morte, inspiram alguns sonetos e odes sobre a ingratidão. Critica-se assim, ainda que de uma forma quase sentimental, a sociabilidade da Corte:

\footnotetext{
Honras que a cega gente tanto preza,

Glorias, que de inconstancia são seguidas,

Acções do vulgo insano repetidas,

Impulada soberba, vil riqueza [...]

De mim nunca sereis appetecidas, [...].

(Apud Borralho, 2008: 92)
}

Mas é nas coleções do século XIX que se tornam mais frequentes os poemas de temática política. Nos manuscritos dispersos das nossas bibliotecas, ao lado de Bocage (Bocage, s.d.: 1046-48), aparecem as glosas de Catarina de Lencastre ao célebre mote: "Defender os pátrios lares,/ Dar a vida pelo Rei,/ É dos Lusos valorosos/ Carácter, Costume e Lei" (Borralho, 2008: 107). Não encontramos outros nomes femininos. As coleções do século XIX reúnem também os poemas da última década do século XVIII. Ficamos por eles a saber que se Interessou pela evolução política da Revolução Francesa. Da mesma forma que louvara a ação do Marquês de Pombal e o lamentara no seu desterro, revoltou-se com 
a morte de Luís XVI, na praça pública. Mas agora não se trata de uma temática sentimental ou social (a ingratidão, a inveja, o infortúnio). Surgem mais explícitas as posições ideológicas e políticas:

França triste, e lastimoza,

[...] De que te serve a quimera

Da liberdade sonhada,

Se hes por huma sombra van

Do proprio sangue banhada!

Artes, Sciencias, riquezas,

Os monumentos sublimes

São hoje substituidos

Pelos mais infames crimes.

(Apud Borralho, 2008: 155) $^{2}$

Tudo isto denuncia uma atitude nova da mulher-poetisa, talvez tida por viril, pouco feminina. É sobretudo espantoso verificar que a autora assume até, em contexto de guerra, essa virilidade da mulher-soldado: lamenta frequentemente não poder seguir os militares, e lutar ao seu lado, de espada em riste. Na partida do regimento português que ajudaria a libertar a família real espanhola do "desterro" de Cádis, queixa-se dos limites que lhe são impostos pelo seu sexo:

[Deus] Já que esta alma me deu, melhor fizera

Se aos campos, aonde ides colher louros,

Eu seguir-vos pudera.

Mas nem sempre, na ordem que nos rege,

Vem o poder unido com o desejo.

(Apud Borralho, 2008: 157) ${ }^{3}$

Poderíamos pensar que o faz à sombra do seu marido, escudada pela sua política durante a Guerra das Laranjas, ou procurando nos seus salões fazer a defesa dessa política, à altura de um êxito duvidoso ou provisório. Mas (paradoxalmente?) é quando Luís

\footnotetext{
${ }^{2}$ Em Araújo de Azevedo, na Marquesa de Alorna, em José Agostinho de Macedo e até em Filinto, se nota esta passagem da simpatia pela Revolução, volvida, depois de 1792, ardor antirrevolucionário. Cf., Joaquim Pintassilgo, "A Revolução Francesa na perspetiva de um diplomata português. A correspondência oficial de António de Araújo de Azevedo" e M. Helena Vilas-Boas e Alvim, "A Marquesa de Alorna - de defensora das Luzes a agente contra-revolucionária" (AA. VV., 1988: 131 ss., 265 ss).; Andrade, 2004: II, passim, max. 116 ss.; Dominique Lecloux, "Un exilé portugais témoin de la révolution française: Filinto Elísio" (AA. VV., $1992: 97$ ss.).

3 Sobre a crescente presença da mulher nas revoltas públicas, nomeadamente no período mais aceso da Revolução Francesa, v.g., Arlette Farge - "Évidentes émeutières" in AA. VV. — Histoire des Femmes, máx. p. 484 ss..
} 
Pinto de Sousa morre, e ela se afasta das festas e assembleias de Lisboa, que a sua voz se torna mais potente e ousada, ela a "Viscondessa velha", no Porto ou no Funchal, que, com 60 ou mais de 70 anos, ao viver a guerra, sobe aos palcos e aclama o espírito bélico (Barros, 1927: II, 111-112): "Nasci livre, amo as leis, Principes e Patria;/ E o que escravo quer ser, escravo seja" (Apud Borralho, 2008: 162).

Tais atitudes serão tanto mais estranhas, quanto mais crentes formos na historiografia literária do século XIX, que nos traçou o retrato das senhoras de salão, ridículas na sua ambição de parecerem intelectuais, como os homens: "Chegam as românticas: D. Francisca Possolo, [...] primeira musa dos salões românticos de Lisboa, a galante Viscondessa de Balsemão, boneca raciocinadora, conversadora subtil, pequena tanagra vestida com a saia de balão da Imperatriz Eugenia." (Resende, 1867: 4).

A citação do Marquês de Resende é, nas personagens e nas modas, uma fantasia literária mais do que uma reconstituição das memórias de infância. Os tempos nele descritos confundem-se num único espaço. Do lado da poesia feminina, fica ainda o sentimentalismo temático, a superficialidade dos raciocínios, a ligeireza da conversação, a futilidade da moda, a neutralidade do salão. Mas a vida e a poesia de Catarina de Lencastre parecem desmentir toda a historiografia romântica que opõe de forma sistemática a disciplina à liberdade, o destino à vontade, a passividade à revolta. $\mathrm{E}$ nem o facto de a poesia de Catarina de Lencastre ser circunstancial ou dedicada a um específico evento, individual ou coletivo, pode servir de argumento para ver nela uma reprodução da literatura cortesã e ritual. Sob a transformação do espaço feminino (no salão ou no palco, agora provisoriamente "lugar-comum"), se visa uma invasão do espaço masculino, o espaço dito público.

Num soneto que dirige a Catarina de Lencastre, Tolentino celebra o final da guerra das Laranjas, agradecendo a Luís Pinto de Sousa, a devolução do galego e das mulas, (Tolentino, 1861: 115), É numa mulher, Catarina de Lencastre, que encontramos a celebração da atitude bélica. Como se também aqui se invertessem as funções tipificadas dos dois sexos, ainda que a gradação regressiva os una, num idêntico horror à morte de que se veem se súbito rodeados: "Mas grita a voz no peito valeroso:/ Ó Pátria! ó honra! ó sacrifício! ó morte!" (Apud Borralho, 2008: 125).

Há em Catarina de Lencastre uma impertinente juventude que hoje avaliamos de forma imperfeita. O neto da Marquesa de Alorna recorda-se de ver Catarina de Lencastre no Teatro de S. Carlos, em Lisboa. Corria o ano de 1821, e teria ela quase 72 anos. Até ao início do século, e durante três largas décadas, tinham estado as mulheres proibidas de subir ao palco... 
Vi muitas vezes a velha Viscondessa de Balsemão, viúva do famoso Ministro Luiz Pinto, avó do actual Visconde, contemporanea e amiga de minha Avó e sua rival como poeta, bater as palmas, pedir silêncio á plateia e recitar varias odes e sonetos em louvor do General em chefe do Exercito revolucionário, Gaspar Teixeira, seu proximo parente. Bernardo Gorjão Henriques, que morreu Ministro de Estado, muitas vezes do seu camarote repetia os seus versos. (Fronteira, 1986: I-II, 212)

Lembra-se ele, José Trazimundo Mascarenhas Barreto, de conhecer o jovem Garrett nas mesmas circunstâncias:

Foi numa d'essas noites de grandes [sic] enthusiasmo que, estando na plateia geral, vi pôr-se de pé sobre um dos bancos um jovem, elegante pelas suas maneiras, d'uma physionomia sympathica e toilette apurada, um pouco calvo, apesar da pouca edade, o qual, pedindo silencio aos que o rodeavam, disse: Á Liberdade. E recitou uma bella ode que foi estrepitosamente applaudida, perguntando-se com curiosidade, tanto nos camarotes, como na plateia, quem era o jovem poeta: foi elle proprio quem satisfez a curiosidade, dizendo chamar-se Garrett. Foi a primeira vez que os habitantes da capital ouviram a voz sonora do grande poeta. (Fronteira, 1986: I-II, 212)

Porque esquecemos estes dados, estes poemas, estas autoras?

Porque nem sempre esquecemos por boas razões.

Catarina de Lencastre foi sendo esquecida porque não podia ser lida, dispersos que ficaram os manuscritos, adiadas que foram sendo as edições impressas. Sem textos, a autora foi desaparecendo da História da Literatura. Sem leitores, é mal citada e confundida. Frederick Bouterwek regista o nome em vida da autora na História da Literatura Espanhola e Portuguesa, mas depois baralha-se na bibliografia. Em 1813, Sismonde de Sismondi, referindo explicitamente a obra de Bouterwek, sublinha a importância daquela "mulher justamente célebre de Portugal", mas depois confunde-lhe a família. O Résumé de l'Histoire Littéraire du Portugal, de Ferdinand Denis, em 1826, refere a sua celebridade, dá-a como exemplo da dita "literatura feminina", mas o autor parece não ter lido qualquer obra sua. Francisco Freire de Carvalho, no Primeiro Ensaio sobre a Historia Litteraria de Portugal, de 1845, lamenta explicitamente o facto de não conhecer nenhuma obra impressa da Viscondessa de Balsemão, embora lhe tivessem passado pelas mãos, na sua juventude, uma coleção de fábulas "dignas de muito louvável estimação" (Carvalho, 1845: 256). Ao longo de 1845, parece existir um renovado interesse pela obra de Catarina de Lencastre. Ernestina de Almeida, em 1842, diz ter intenção de publicar algumas poesias de Catarina de Lencastre. Entre 1838 e 1842, a Revista Literária, do Porto, publica da autora oito fábulas. 
Tanto o Almanach de lembranças luso-brasileiro, organizado por Alexandre Magno Castilho, entre 1857-1862, como a Miscelanea poetica, de 1851-1852, publicam meia dúzia de poemas de Catarina de Lencastre. Um texto crítico de José Osório, na Illustração, em 1845, e o Diccionario Bibliographico de Inocêncio Francisco da Silva, editado em 1860, registam a leitura de alguns dos seus papéis. Sol de pouca dura. Ernestina de Almeida não chega a editar-Ihe a antologia. Os poemas dos periódicos confirmam a dispersão do "corpus". Confundir-lhe o nome, a vida ou a obra é uma natural fatalidade. António Feliciano de Castilho, em 1862, num texto das Novas Telas Literarias, coloca-a num imenso rol de setecentistas injustamente esquecidos .... Mas infelizmente chama-lhe Josefa de Balsemão. De Catarina de Lencastre já só falariam, no século XIX, alguns manuseadores de papéis velhos: Camilo Castelo Branco (para reescrever o Curso de Literatura), António da Costa (em A Mulher em Portugal), e, no século XX, Tereza Leitão de Barros (em Escritoras de Portugal), Depois o silêncio toma conta do nome, da vida e da obra de Catarina de Lencastre (Borralho, 1999: I, 20-27).

Não devíamos todavia esquecer a estratégia das poetisas que não se restringem aos temas sentimentais, próprios da mulher e da poética dita "romântica", "infelizmente pouco femininos", como lamenta José Osório de Oliveira (Oliveira, s.d.: 45). Não devíamos ignorar a ousadia de quem recusou o espartilho do sexo e da idade, publicando com o seu nome. Pois quantas autoras conhecemos, ainda daquelas que escreveram no final do século XIX, que ousaram cantar o desejo, o desejo que toda a mulher honesta estava obrigada a calar? Bem ousados deviam soar aqueles versos femininos que, à maneira dos de Anacreonte, reivindicavam agora para as mulheres idosas o direito a não calar o desejo físico:

\footnotetext{
Posto que entre os meus cabelos

Comece a neve a cair, Inda sinto aquele fogo

Com que o posso desmentir.

[...] Quando passaram três dias

Sem que... nem quero dizê-lo,

Tu me desses vivas provas

De um carinhoso desvelo?

(Borralho, 1999: II, R374-6)
}

Estrategicamente, só na última estrofe ficamos a saber que estas seriam palavras de Safo. Mas ainda mais estranha nos parece esta Safo velha, de cabelos brancos, uma Safo imaginada e inverosímil e não uma Safo histórica. Sentidos ou fingidos, os versos sobre o desejo são, em qualquer caso, a imaginação de uma outra forma de dizer a mulher, de falar sobre ela (cf. Borralho, 2008: 95-96) 
O tema destas mulheres viris, sexualmente possuidoras de uma voz ativa, encontrase em muitas personagens literárias, com muitas variantes simbólicas. Encontra-se certamente na supervisão de Hera, no desprezo de Artémis pelos homens, na vingança de Medeia, nos mitos das Amazonas, das Valquírias, das Fúrias e das Bacantes, ou das donzelas que se disfarçam de soldado, formas singulares ou coletivas de uma força poderosa mas dissimulada. Muitos romances do século XVIII tornaram protagonista a mulher que se disfarça de homem: Marthésie, première reine des Amazones, de La Motte (1699), L'Amazone Française, de Marie-Jeanne L'Héritier de Villandon (1718), Le Faux Chevalier de Warwick, de Dupré d'Aulnoy (1736), les Mémoires de Mlle de Mainville ou Le Feint Chevalier, de D'Argens (1736), Les Amazones, de Anne Marie du Bocage (1749), Corinne, de Mme de Staël (1807). Louis Rustaing de Saint-Jorry imaginará uma sociedade utópica de mulheres-soldado (Les Femmes Militaires, de 1735) e a lista poderia alongar-se (cf. Fauchery, 1972: 626-627; AA. VV., 2004 : 29-47). Mulheres varonis em espaços domésticos (cf. Anastácio, 2005 ).

Mulheres em tudo semelhantes aos homens.

E porque não? me respondeu ela. O Autor da Natureza não pôs mais diferença entre as mulheres e os homens do que a necessária para a propagação. Nós temos como eles braços, pernas, e todas as faculdades intelectuais, e o valor, a habilidade, e a disciplina decidem ainda mais do que a força, da sorte dos combates; e nós podemos adquirir como eles todas estas qualidades, sendo conduzidas por uma boa educação. [...] A experiência tem mostrado até agora que, à excepção da força, não há uma só coisa em que elas sejam inferiores aos homens. (Anón., $1790:$ I, XV)

Isto afiança uma mulher-soldado, num livro de Luís Altina de Campos. A esta personagem se poderia todavia juntar o da filha desobediente, a que contesta os termos do seu casamento, acordado pelo pai ou pelo tutor. Ou o da "pastora extravagante", que ama de forma diferente, respondendo à sua consciência e vontade. Ou Heloísa, mais do que a histórica autora de cartas a Abelardo: o século XVIII reinventa-a e torna-a um símbolo de afirmação do desejo amoroso (Borralho, 2002: 267-86). A personagem de uma tragédia igualmente escrita por Catarina de Lencastre, Cora, virgem do Templo do Sol (que perde a virgindade e por isso enfrenta o sacrifício da fogueira), é também uma revoltada Heloísa, presa aos rituais coletivos, vítima do emparedamento social em que Abelardo e a sociedade a encerrou: "Em outros Povos não he crime o amor..." (Apud Borralho, 2008: 337).

Mas estas mulheres reais, que escrevem contra os invasores, evadindo-se da sua condição - mulheres que encararam a pena literária como uma espada circunstancial e o 
ornato como um escudo, na verdade "viajantes aéreas", para retomar a curiosa metáfora de Olympe de Gouges -, parecem-nos ainda mais interessantes.

Até porque, como vem a responder Frei José de S. Cyrillo Carneiro ao frequentador da Igreja de São Paulo, não havia razão para duvidar do pregador em nenhuma das duas situações referidas. Está bem o que acaba bem: próprio do bom cristão é perdoar e "amar o próximo", ainda que invasor. Próprio da mulher cristã é viver recatadamente, cuidando da sua honra quando tem de sair de casa.

Significativo, afinal, é que, entre os que nos invadem e os que se evadem, julguemos menos próximos os que se evadem. 


\section{Bibliografia}

[M. D.] (1789). Discurso que fizerão duas Senhoras portuguezas depois de lerem o papel dos Conselhos que deu hum Brazileiro a todos os seus Patricios que viessem a esta Corte: a que elle chama Advertencias saudaveis contra o genero feminino. Dialogo entre Marcina e Delmira. Lisboa: Off. Francisco Borges de Sousa.

[S. A.] (1782). Instruçõens ás Senhoras Cazadas para viverem em paz, e quietação com seus Maridos. Lisboa: Off. Simão Thaddeo Ferreira.

[S. A.] (1788). Assemblea Curiosa, e Observador Academico, distribuíde em Folhetos para Utilidade dos Curiosos. Lisboa: Off. Simão Thaddeo Ferreira.

[S. A.] (1789). Disputa divertida das grandes Bulhas, que teve hum homem com sua Mulher, por lhe não querer deitar huns fundilhos n'huns calççoens velhos. Lisboa: Off. Francisco Borges de Sousa.

AA.VV (1988). A Revolução Francesa e a Península Ibérica. Actas do Colóquio, coord. Vítor Neto. Coimbra: Universidade de Coimbra.

AA. VV. (1991). Histoire des Femmes, Vol. XVIe-XVIIle, dir. N. Z. Davis et Arlette Farge. Paris : Plon.

AA. VV. (1992). A Recepção da Revolução Francesa em Portugal e no Brasil. Actas do Colóquio (2-9 de Novembro de 1989). 2 vols. Porto: Universidade do Porto.

AA. VV. (2004). Femmes des Lumières. Paris : PUF/SFEDS.

AA. VV. (1989) Les Femmes et la Révolution Française. 2 vols. Toulouse : Univ. de Toulousele-Mirail.

ANASTACIO, Vanda $\left(2005^{\mathrm{a}}\right)$. «Cherchez la Femme». À propos d'une force de sociabilité littéraire à Lisbonne à la fin du XVIIle siècle. Sep. "Arquivos do Centro Cultural Português », vol. XLIX : « Sociabilités intellectuelles XVI-XX siècles. Paris : C. C. C. Gulbenkian, pp. 93101.

$\left(2005^{b}\right)$. Mulheres varonis e interesses domésticos. Reflexões acerca do discurso produzido pela História Literária acerca das mulheres escritoras da viragem do século XVIII para o século XIX. Sep. "Cartographies. Mélanges afferts à Maria Alzira Seixo. Lisboa: [s.n.?], pp. 537-556.

ANDRADE, Maria Ivone de Ornellas de (2004). A Contra-Revolução em Português. José Agostinho de Macedo. Lisboa: Colibri.

AnóN. [Luis Caetano Altina de Campos] (1790). Viagens d'Altina nas cidades mais cultas da Europa, Lisboa: Off. Simão Taddeo Ferreira.

ARAúJo, Ana Cristina (2003). A Cultura das Luzes em Portugal. Lisboa: Livros Horizonte. (2004). "O Filósofo Solitário" e a esfera pública das Luzes". In "Estudos em

Homenagem a Luís A. de Oliveira Ramos". Porto: FLUP, pp. 197-210. 
ARISTOTLE (1994). The Works of, ed. Mortimer J. Adler. 2 vols. Chicago-Auckland-London etc.: Encyclopaedia Britannica.

BADINTER, Elisabeth (1983). Emile, Emile. L'ambition féminine au XVIII siècle. Paris : Flammarion.

BARROS, Thereza Leitão de (1927). Escritoras de Portugal. Génio Feminino revelado na Literatura Portuguesa. 2 vols., Lisboa: s.e., t. II, pp. 102-116).

BINGRE, F. Joaquim (1850). O moribundo Cysne do Vouga, collecção de algumas peças mais importantes [....] Porto: Typ. Commercial.

BocAge (s.d.). Obras de... Porto: Lello.

BorRalHo, Maria Luísa Malato (2002). "O Mito de Abelardo e Heloísa na Poesia Portuguesa de Setecentos". In Revista da Faculdade de Letras da Universidade do Porto. Série II: Línguas e Literaturas. Porto: $\mathrm{n} .{ }^{\circ} \mathrm{XIX}$, pp. 267-286 (2004). "Porque é que a História esqueceu a Literatura Portuguesa do século XVIII". In Literatura e História. Actas do Colóquio Internacional. Porto: vol. I, pp. 63-83 (2008). Por acazo hum viajante... .Lisboa: IN-CM (1999). D. Catarina de Lencastre (1749-1824). Libreto para uma autora quase esquecida, tese de doutoramento apresentada à Faculdade de Letras da Universidade do Porto. 2 volumes. Porto: FLUP.

CARneIRO, Fr. José de S. Cyrillo (1811). Carta e Resposta sobre o bodio dos inimigos francezess, e sobre o ornato das mulheres, occasionadas por hum Sermão, que se pregou no Igreja de S. Paulo da Cidade de Lisboa, no primeiro de Janeiro de 1811, e publicadas por hum intimo amigo do Pregador... Lisboa: Impressão Regia.

Carvalho, Francisco Freire de (1845). Primeiro Ensaio sobre a História Litteraria de Portugal desde a sua mais remota origem até o presente tempo, seguido de differentes opusculos que servem para sua maior illustração... Lisboa: Ed. Rollandiana.

CARVALHO, José Liberato Freire de (1982). Memórias da vida de.... introd. João Carlos Alvim. $2^{\underline{a}}$ ed. Lisboa: Assírio e Alvim.

CHARTIER, Roger (1990). As práticas da escrita. In "História da Vida Privada. Do Renascimento ao Século das Luzes" dir. Ph. Ariès. Porto: Afrontamento, p. 113 ss. CostA, José Daniel Rodrigues da (1788). Petas da Vida ou A Terceira parte dos Opios. Lisboa: Off. Simão Thaddeo Ferreira.

DARMON, Pierre (1983). Mythologie de la Femme dans l'Ancienne France (XVI - XIX siècle. Paris : Editions du Seuil.

FACA, Zacarias Alves (1823). Academia das Mulheres ou o Liberalismo do Século Combatido até pela Fraqueza deste Sexo. Coimbra: Imprensa da Universidade.

FAUCHERY, Pierre (1972). La Destinée Féminine dans le Roman Européen du Dix-Huitième Siècle (1713-1807). Paris : Armand Colin. 
FENTRESS, James / WICKHAM, Chris (1994). Memória Social [ed. port. Social Memory, 1992], trad. Telma Costa. Lisboa: Teorema.

FigueIREDO, Manuel de (1804). Theatro. Lisboa: Impressão Regia, t. V.

FRONTEIRA e D'AlorNA, Marquês de [José Trazimundo Mascarenhas Barreto] (1986). Memórias do... ditadas por êle próprio em 1861, fac-simile da ed. Ernesto de Campos de Andrada, 5 vols. Lisboa: Imprensa Nacional-Casa da Moeda.

GONÇALVES, Rui (1992). Dos privilegios \& praerogativas q. ho genero feminino tê por direito comû \& ordenações do Reyno mais que ho genero masculino, ed. fac-similée, avec Dédicatoire et Prologue de la 2.ème édition, de 1785, presentée par Elisa Maria Lopes da Costa. Lisboa: B.N.L.

Gouges, Olympe (1791). Déclaration des Droits de la Femme et de la Citoyenne, 1791, disponível em : http://www.cndp.fr/laicite/pdf/Gouges.pdf (consultado 31/1/2009).

HERDER (1987). Ensaio sobre a origem da linguagem, trad. J. Justo. Lisboa : Antígona. MALATO, Maria Luísa; PARMENTIER, Isabelle; DESTAIN, Christian (2009). Le XVIIle Siècle: une époque d'Ombres et de Lumières, ed. Anne Staquet, Mons : Ed. Université.

Melo, Francisco Manuel de (2003). Carta de Guia de Casados, ed. Maria de Lurdes Correia Fernandes. Porto: Campo das Letras.

OLIVEIRA, José Osório de (s.d). [Panorama de] La littérature portugaise, trad. J. Bayle. Lisboa : S.N.I.

RAMOS, Luís A. de Oliveira (1994). "Notas sobre o Trajar dos Portugueses à Revolução Francesa", Sep. "Intercâmbio", n. ${ }^{\circ}$ 5, Porto : pp. 7-19.

RESENDE, Marquês de (1868). Pintura de um outeiro musical às portas de Lisboa no fim do século passado, feita e lida no primeiro serão litterario do Gremio Recreativo em 12 de Dezembro de 1867 pelo... Lisboa: Typ. da Academia Real das Sciencias.

Rousseau (1971). CEuvres Complètes, 3 vols. Paris : Seuil.

Roussel (1845). Système Physique et Moral, nouv. Edition. Paris : Charpentier et Fortin, Masson et C.ie.

SAINT-JORY, L. Rustaing (1735). Les Femmes Militaires. Paris : C. Simon.

SILVA, Maria Regina Tavares da (1999). A Mulher. Bibliografia portuguesa anotada (Monografias, 1518-1998), pref. M. de Lurdes Pintasilgo. Lisboa: Cosmos.

SILVA, V. M. Aguiar e (2002). Teoria da Literatura, 8. ${ }^{a}$ ed. Coimbra: Almedina. Tolentino [de Almeida], Nicolau (1861). Obras Completas de... Lisboa: Typ. de Castro, \& Irmão. 
